\title{
Totalitas Kehidupan Pesantren: Tinjauan Historis Pemikiran K.H. Abdullah Syukri Zarkasyi tentang Konsep Pendidikan yang Ideal di Indonesia (1985-2011)
}

\author{
SaifuddinAlif Nurdianto ${ }^{1}$, Ajat Sudrajat ${ }^{2}$ \\ ${ }^{1}$ Mahasiswa Magister Pendidikan Sejarah Universitas Sebelas Maret \\ ${ }^{2}$ Dosen Program Studi Pendidikan Sejarah, FIS, Universitas Negeri Yogyakarta
}

\begin{abstract}
Abstrak
Tujuan penelitian ini untuk menjelaskan konsep pendidikan ideal yang ditawarkan K.H. Abdullah Syukri Zarkasyi (1985-2011) dan pengaruh pemikirannya dalam bidang pendidikan.

Penelitian menggunakan metode penulisan sejarah Kuntowijoyo dengan lima tahapan, yaitu pemilihan topik, heuristik, verifikasi, interpretasi, dan historiografi. Sumber data berupa sumber primer dan sekunder yaitu arsip, dokumen, rekaman pidato, foto, majalah, wawancara, dan buku.

Hasil penelitian menunjukkan bahwa dasar filosofis pendidikan yang dikembangkan oleh K.H. Abdullah Syukri Zarkasyi adalah Panca Jiwa. Konsep pendidikan yang ditawarkan K.H. Abdullah Syukri Zarkasyi (1985-2011) adalah totalitas kehidupan dalam dunia pendidikan, pendidikan integral yang dipengaruhi konsep integrasi ilmu dari K.H. Ahmad Dahlan, tri pusat pendidikan yang dipengaruhi pemikiran Ki Hadjar Dewantara, dan konsep jiwa merdeka yang dipengaruhi konsep K.H. Imam Zarkasyi. Adapun pengaruh pemikiran K.H. Abdullah Syukri Zarkasyi secara internal adalah berkembangnya PMDG menjadi sembilan belas cabang pada masa kepemimpinannya dan bertambahnya jumlah santri dan tenaga pengajar di PMDG dengan presentase 5\% selama tiga tahun terakhir. Pengaruh eksternalnya adalah sistempendidikan di PMDG mendapatkan pengakuan dari dunia internasional, diadopsi oleh banyak lembaga pesantren, dan memberikan inspirasi terhadap gagasan dar itokoh-tokoh masyarakat.
\end{abstract}

Kata Kunci: pendidikan, K.H. Abdullah Syukri Zarkasyi, PMDG

\section{Pendahuluan}

Pemikiran K.H. Abdullah Syukri Zarkasyi tentang konsep pendidikan yang ideal di Indonesia (1985-2011) melewati dua masa pemerintahan, Orde Baru dan Reformasi. Politik pemerintahan Orde Baru menekankan kepada uniformitas di dalam berpikir dan bertindak yang mengarah kepada terbentuknya masyarakat homogen. Stabilitas politik dan keamanan menjadi doktrin utama untuk mencapai perkembangan ekonomi yang tinggi. ${ }^{1}$ Politik ini berdampak kepada pelaksanaan pendidikan nasional yang semacam alat penyeragaman guna menunjang stabilitas dan keamanan nasional yang dilakukan oleh sekelompok elit politik. ${ }^{2}$

Tahun 1998 menjadi awal perubahan politik nasional dengan munculnya gerakan reformasi. Perbaikan tata kelola pemerintahan menjadi tujuan utama pada masa ini, termasuk dalamhal

1H.A.R. Tilaar, Paradigma Baru Pendidikan Nasional, (Jakarta: RinekaCipta, 2010), hlm. 3. 2Ibid.,hlm. 5. 
pendidikan. Hal ini dibuktikan dengan amandemen Undang-Undang Dasar (UUD) 1945 dengan menambahkan beberapa ayat dalam pasal 31 yang mengatur tentang pendidikan. Pemerintah daerah diberikan kewenangan untuk ikut serta dalam pelaksanaan pendidikan nasional dengan lahirnya Undang-Undang (UU) Republik Indonesia (RI) No. 22 tahun 1999 tentang pemerintahan daerah. Sistem pendidikan nasional juga diperbaiki dengan lahirnya UU RI No. 20 Tahun 2003 tentang sistem pendidikan nasional. ${ }^{3}$

Perubahan paradigma pendidikan nasional dari masa pemerintahan Orde Baru ke masa Orde Reformasi sebenarnya tidak banyak berpengaruh terhadap pelaksanaan pendidikan di Pondok Modern Darussalam Gontor (PMDG) yang dipimpin oleh K.H. Abdullah Syukri Zarkasyi. Hal ini dikarenakan pendidikan yang dilaksanakan oleh K.H. Abdullah Syukri Zarkasyi di PMDG telah memiliki sistem tersendiri sejak awal berdiri dan tidak berkaitan dengan sistem pendidikan nasional.

K.H. Abdullah Syukri Zarkasyi memiliki gagasan-gagasan yang menarik untuk memperbaiki kualitas pendidikan di Indonesia. Pemikirannya tidak sekedar wacana di atas kertas, namun telah dia laksanakan di lembaga pendidikan yang

${ }^{3}$ Anonim, Konstitusi UUD 1945 dan Amandemen I,II, III \& IV, (Yogyakarta: Pustaka Timur, 2009), hlm. 66-78. dipimpinnya saat ini, Pondok Modern Darussalam Gontor (PMDG). Penulisan ini terbatas pada pemikiran K.H. Abdullah Syukri Zarkasyi antara tahun 1985 sampai tahun 2011. Tahun 1985 adalah tahun pertama K.H. Abdullah Syukri Zarkasyi memimpin PMDG, dan 2011 adalah tahun dimana dia mengalami sakit sehingga tidak bisa melakukan aktifitas dengan baik. ${ }^{4}$

\section{Tinjauan Pustaka}

Kajian pustaka adalah adalah telaah terhadap pustaka atau literatur yang menjadi landasan pemikiran dalam penelitian. ${ }^{5}$ Tujuan dari kajian pustaka adalah untuk memberikan informasi kepada pembaca tentang hasil-hasil penelitian lain yang berkaitan erat dengan penelitian yang dilakukan saat itu, menghubungkan penelitian dengan literatur-literatur yang ada, dan mengisi celah-celah dalam penelitian-penelitian sebelumnya. ${ }^{6}$

$$
\text { Penjelasan mengenai tujuan }
$$

pendidikan nasional (1985-2011) menggunakan buku Landasan dan Arah Pendidikan Nasional Kita karya Soedijarto

\footnotetext{
${ }^{4}$ Tahun 2011 K.H. Abdullah Syukri Zarkasyi sakit stroke, sehingga mengalami kesulitan untuk berkomunikasi.

5Jurusan Pendidikan Sejarah, Pedoman Penulisan Tugas Akhir Skripsi Program Studi Pendidikan Sejarah FIS UNY, (Yogyakarta: Prodi Pendidikan Sejarah FIS UNY, 2013), hlm. 3.

${ }^{6}$ Creswell, John W., "Research Design: Qualitative, Quantitative, and Mixed Approaches", alihbahasa. Ahmad Fawaid, Research Design: Pendekatan Kualitatif, Kuantitatif, dan Mixed, (Yogyakarta: Pustaka Pelajar, 2010), hlm. 40.
} 
yang diterbitkan oleh Kompas Media Nusantara tahun 2008. Buku ini memberikan kritik atas kesalahan pelaksanaan pendidikan dari masa Orde Baru sampai Orde Reformasi, sekaligus memberikan gagasan tentang arah pendidikan Indonesia untuk masa yang akan datang.

Buku kedua yang digunakan adalah Paradigma Baru Pendidikan Nasional karya H.A.R. Tilaar yang diterbitkan oleh Rieneka Cipta tahun 2002. Buku ini memberikan refleksi pendidikan nasional pada masa lalu, Orde Lama dan Orde Baru, sekaligus menjelaskan tantangan pelaksanaan pendidikan di masa Orde Reformasi. Gagasan menarik yang juga diulas dalam buku ini adalah, agama memiliki peran penting sebagai pegangan hidup manusia di tengah-tengah kemajuan ilmu pengetahuan. $^{7}$

Penjelasan mengenai pendidikan yang ditawarkan K.H. Abdullah Syukri Zarkasyi (1985-2011) menggunakan buku Hermeneutika Ilmu Sosial karya Paul Ricoeur yang telah diterjemahkan ke Bahasa Indonesia yang berisi tata cara penggunaan ilmu hermeneutika untuk penulisan ilmuilmu sosial.Buku kedua yang digunakan berjudul Psikologi Agama karya Jalaluddin yang diterbitkan oleh Rajawali Press tahun 2015. Buku ini menjelaskan tata cara meneliti pemikiran seseorang dengan latar

${ }^{7}$ H.A.R. Tilaar, op.cit., 146. belakang keagamaan. Dua buku ini digunakan menelaah pemikiran K.H. Abdullah Syukri Zarkasyi tentang konsep pendidikan yang ideal di Indonesia (19852011).

Pengaruh pemikiran KH. Abdullah Syukri Zarkasyi terhadap perkembangan PMDG dijelaskan dengan menelaah buletin warta dunia yang diterbitkan oleh PMDG. Warta dunia adalah buletin tahunan yang berisi tentang laporan kegiatan-kegiatan yang telah dilaksanakan di PMDG selama satu tahun.

\section{Metode Penelitian}

\section{A. Pemilihan Topik}

Pemilihan topik digunakan karena sejarah memiliki topik bahasan yang luas sehingga harus ditentukan topik mana yang akan diteliti. Pemilihan topik didasari oleh dua syarat yaitu kedekatan emosional dan kedekatan intelektual. ${ }^{8}$ Penulis memilih topik pandangan KH. Abdullah Syukri Zarkasyi tentang konsep pendidikan yang ideal di Indonesia. Kedekatan emosionalnya adalah, ketertarikan penulis terhadap metode pendidikan K.H. Abdullah Syukri Zarkasyi yang dia terapkan di PMDG.

Penulis menganggap metode pendidikan yang diterapkan oleh K.H. Abdullah Syukri Zarkasyi di PMDG berbeda dengan metode pendidikan pada umumnya. Satu hal yang menarik juga dari K.H.

${ }^{8}$ Kuntowijoyo, Pengantar Ilmu Sejarah, (Yogyakarta: Bentang Pustaka, 1995), hlm. 21. 
Abdullah Syukri Zarkasyi adalah, pemikirannya konsisten untuk melaksanakan pendidikan secara mandiri dengan model pesantren, tanpa berkiblat kepada sistem pendidikan nasional.

Kedekatan intelektualnya adalah, penulis merasa konsep pendidikan yang ada di PMDG bisa menjadi alternatif untuk memperbaiki masalah pendidikan di Indonesia. Ketersediaan sumber juga menjadi salah satu alasan penulis untuk mengkaji pemikiran K.H. Abdullah Syukri Zarkasyi tentang konsep pendidikan yang ideal di Indonesia (1985-2011).

\section{B. Pengumpulan sumber}

Pengumpulan sumber harus berkaitan dengan tema yang akan diteliti. Penelitian ini menggunakan dua jenis sumber, primer dan sekunder yang diklasifikasian berdasarkan penulis sumbersumber tersebut.

Sumber primer adalah yang ditulis oleh pelaku sejarah, meskipun sumber tersebut ditulis setelah peristiwa tersebut terjadi. Sumber primer diperoleh di Kantor Redaksi Majalah Gontor, Perpustakaan PMDG, Kantor Sekretasis Pimpinan PMDG, dan Perpustakaan Universitas Islam Negeri (UIN) Sunan Kalijaga Yogyakarta.

Sumber primer yang digunakan adalah dua buku karya K.H. Abdullah Syukri Zarkasyi yang berjudul Manajemen Pesantren; Pengalaman Pondok Modern Gontor dan untuk Pemimpin; Pengalaman Memimpin Gontor, artikel dari K.H. Abdullah
Syukri Zarkasyi yang dimuat di Majalah Gontor edisi tahun 2011 sampai 2016, dan buletin tahunan Warta Dunia tahun 2005 sampai 2016.

Sumber sekunder adalah sumber yang ditulis oleh orang yang tidak terlibat langsung dalam peristiwa sejarah. Sumber sekunder didapatkan dari situs resmi perpustakaan pusat Universitas Islam Negeri (UIN) Syarif Hidayatullah Jakarta dengan alamat Url: www.tulis.uinjkt.ac.id.

Sumber sekunder yang digunakan sebagai perbandingan dengan melihat pemikiran KH. Abdullah Syukri Zarkasyi dari perspektif orang lain. Sumber sekunder yang didapatkan adalah skripsi dari Iswahyudi yang berjudul "Pemikiran $\mathrm{KH}$. Abdullah Syukri Zarkasyi, MA tentang Pendidikan Pesantren Modern".

\section{Verifikasi (Kritik Sumber)}

Kritik sumber adalah proses menyaring sumber secara kritis, terutama terhadap sumber-sumber primer, agar diperoleh fakta hasil penulisan. Tujuannya adalah agar hasil penulisan sejarah merupakan produk dari suatu proses ilmiah yang dapat dipertanggungjawabkan, bukan hasil dari fantasi, manipulasi, atau fabrikasi. ${ }^{9}$

Kritik sumber terdiri dari kritik eksternal dan kritik internal. Kritik eksternal digunakan untuk menguji secara

\footnotetext{
${ }^{9}$ Helius Sjamsuddin, Metodologi Sejarah, (Yogyakarta: Ombak, 2007), hlm. 103.
} 
fisik keaslian atau otentitas suatu sumber yang dipakai. Kritik ini dilakukan dengan cara meneliti jenis kertas, ukuran kertas, ukuran tulisan, tinta yang digunakan, jenistulisan dan semua hal yang bekaitan dengan fisik penulisan di luar isi yang ditulis. Kritik internal digunakan untuk menguji kredibilitas atau kesahihan sumber terkait dengan isi yang ditulis. ${ }^{10}$

\section{Interpretasi}

Interpretasi adalah penafsiran fakta sejarah dengan merangkai fakta-fakta tersebut menjadi suatu kesatuan yang logis. Penulis menggunakan metode analisis dan sintesis dalam penulisan ini. Penulis menggunakan analisis untuk menelaah pemikiran K.H. Abdullah Syukri Zarkasyi tentang konsep pendidikan yang ideal di Indonesia (1985-201). Penggunaan metode analisis oleh penulis didasarkan pada hasil sintesis yang sudah dilakukan sebelumnya.

\section{E. Historiografi}

Tahapan terakhir dari penulisan sejarah adalah historiografi atau penulisan sejarah. Fakta sejarah yang terkumpul belum bisa ditulis apabila tidak dirangkai sebagai satu kesatuan. Pengalaman dan keahlian penulis dalam merangkai berbagai fakta sejarah mutlak diperlukan, karena inilah yang akan menentukan kualitas daripada tulisan tersebut.

Penulis memaparkan tujuan beserta kritik atas pendidikan nasional masa Orde

${ }^{10}$ Kuntowijoyo, op.cit.,hlm. 99-101.
Baru (1985-2011) dan masa Orde Reformasi (1999-2011) pada bagian pengantar. Hasil penulisan berisi konsep pendidikan yang K.H. Abdullah Syukri Zarkasyi dan pengaruh pemikirannya dalam bidang pendidikan. Kesimpulannya berisi hasil akhir yang menjawab rumusan masalah berdasarkan fakta yang ditemukan.

\section{Hasil Dan Pembahasan}

A. Konsep pendidikan K.H. Abdullah Syukri Zarkasyi (1985-2011)

1. Dasar Filosofis Pemikiran K.H. Abdullah Syukri Zarkasyi tentang Pendidikan

Gagasan K.H. Abdullah Syukri Zarkasyi tentang pendidikan berlandaskan nilai dan filsafat hidup PMDG yang terangkum dalam Panca Jiwa. Panca Jiwa adalah lima hal yang menjadi filsafat hidup warga PMDG dalam melaksanakan pendidikan dan pengajaran. Panca Jiwa terdiri dari Keikhlasan, Kesederhanaan, Berdikari, Ukhuwah Islamiyah, dan Kebebasan.

Pertama, Keikhlasan di sini adalah ikhlas yang aktif, artinya berbuat dengan penuh kesungguhan, bekerja keras, berpikir keras, bersabar keras, dan berdoa keras. Inilah ikhlas yang produktif. ${ }^{11}$ Kedua, sederhana berarti wajar, tidak berlebih-

\footnotetext{
${ }^{11}$ Abdullah Syukri Zarkasyi, "Ikhlas", Majalah Gontor, Edisi 07, Tahun XII, November 2014/Muharram-Safar 1436, hlm. 30.
} 
lebihan. Kesederhanaan mengandung unsur kekuatan dan ketabahan hati dalam menghadapi segala kesulitan. ${ }^{12}$ Ketiga, berdikari berarti tidak menyandarkan kehidupan berdasarkan bantuan orang lain.13 Keempat, adalah Ukhuwah Islamiah atau rasa persaudaraan sesama muslim. Kehidupan di dalam lingkungan pesantren yang diliputi suasana gotong-royong dan rasa persatuan menjadikan peserta didik memiliki ikatan dengan teman-temannya. ${ }^{14}$ Kelima, Kebebasan berarti bebas dalam berpikir, menentukan masa depan, memilih jalan hidup, berjiwa besar, dan optimis dalam menghadapi hidup. ${ }^{15}$

\section{Makna dan Peran Penting Pendidikan}

K.H. Abdullah Syukri Zarkasyi berpendapat bahwa pendidikan adalah segala sesuatu yang kita lihat, kita dengar, dan kita rasakan. ${ }^{16}$ Pendidikan memiliki peran penting dalam upaya memajukan bangsa dan negara. Pendidikan menjadi pilihan yang strategis untuk mengatasi berbagai persoalan, termasuk persoalan sosial yang menimpa generasi muda. Pendidikan yang dimaksud adalah suatu proses yang dibangun di atas landasan ajaran-ajaran agama, serta nilai-nilai

12Imam Zarkasyi, "Panca Jiwa Pondok Pesantren", Majalah Gontor, Edisi 06, TahunXII, Oktober 2014/Dzulhijjah-Muharram 1435, hlm. 96.

${ }^{13}$ Ibid.

${ }^{14}$ Ibid.

${ }^{15}$ Ibid.

${ }^{16}$ Abdullah SyukriZarkasyi, Bekal untuk Pemimpin; Pengalaman Memimpin Gontor, (Ponorogo: Trimurti Press, 2011), hlm. 14. kemanusiaan dan kebangsaan. Syarat untuk melakukan hal-hal tersebut adalah dengan menciptakan pendidikan yang berkualitas. ${ }^{17}$

Pendidikan yang berkualitas harus memiliki dasar nilai yang kuat, sistem yang baik, dan disiplin yang tinggi. Dasar nilai yang kuat menjadi pondasi bagi setiap lembaga pendidikan untuk menerapkan visi pendidikannya. Sistem yang baik apabila mampu bertahan dan menghasilkan sesuatu yang baik, baik dari segi prestasi, kualitas alumni, dan berbagai macam aspek lainnya. ${ }^{18}$

\section{Sistem Pendidikan dari K.H. Abdullah}

\section{Syukri Zarkasyi.}

Pendidikan yang ditawarkan oleh K.H. Abdullah Syukri Zarkasyi adalah pendidikan yang mengajarkan totalitas kehidupan. Konsep ini menekankan pendidikan yang betul-betul menyeluruh, tidak ada satu kegiatanpun yang tidak ada aturannya, semua diatur dengan total quality control. Totalitas kehidupan dilaksanakan dengan mengendalikan siswa dengan total dalam rangka mendidik pola kecerdasan peserta didik, baik secara intelektual-emosional, sosial, maupun

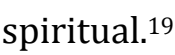

\footnotetext{
${ }^{17}$ Wawancara dengan K.H. Abdullah Syukri Zarkasyi, "Menggagas Pendidikan Berkarakter Ala Gontor", MajalahGontor, Edisi 03, Tahun IX, Juli 2011/Rajab-Sya'ban 1432, hlm. 22. ${ }^{18}$ Ibid.

${ }^{19}$ Abdullah Syukri Zarkasyi, Manajemen Pesantren, (Ponorogo: Trimurti Press, 2005), hlm. 114.
} 
Pembinaan kecerdasan intelektualemosional dilaksanakan dengan menanamkan disiplin kepada peserta didik melalui berbagai kegiatan ekstrakurikuler, intrakurikuler, dan kokurikuler. Aktifitas peserta didik inilah yang akan menciptakan sebuah kehidupan bermasyarakat. Singkat kata, pendidikan yang baik adalah yang mampu menciptakan tatanan kehidupan bermasyarakat di dalam lembaga pendidikan tersebut. ${ }^{20}$

\section{Jawaban atas Problematika}

Pendidikan Nasional (1985-2011)

a. Totalitas Kehidupan dalam Proses Pendidikan

Pendidikan tidak bisa dimaknai sebagai pengajaran, apalagi hanya proses belajar mengajar di dalam kelas. Pendidikan yang baik akan berjalan dengan baik apabila dilaksanakan secara total. Setidaknya ada enam komponen dasar yang harus dilaksanakan dalam proses pendidikan, yaitu pengajaran, penugasan, pembiasaan, pelatihan, pengawalan, dan keteladanan. ${ }^{21}$

Pertama, pendidikan adalah pengajaran. Pengajaran ini untuk melatih aspek kognitif peserta didik. ${ }^{22}$ Kedua, pendidikan adalah penugasan yang diberikan kepada peserta didik untuk menunjang ilmu pengetahuan yang telah

${ }^{20}$ Ibid.,hlm. 114-115.

21Wawancara dengan K.H. Abdullah Syukri Zarkasyi, "Menggagas Pendidikan Berkarakter Ala Gontor", op.cit.,hlm. 21.

${ }^{22}$ Ibid. dia dapat ketika proses belajar di dalam kelas, semakin banyak seseorang mendapatkan tugas, maka akan semakin terampil dalam menyelesaikan segala persoalan hidup. ${ }^{23}$ Ketiga, pendidikan adalah pembiasaan yang terkadang membutuhkan pemaksaan, dengan tujuan agar peserta didik menjadi terbiasa, dan setelah terbiasa akan menjadi sebuah gaya hidup. ${ }^{24}$

Keempat, pendidikan adalah pelatihan yang dilaksanakan untuk melatih peserta didik menghadapi persoalan kehidupan, tidak sekedar teori di dalam kelas. ${ }^{25}$ Kelima, pendidikan adalah pengawalan yang dilakukan agar peserta didik tidak salah dalam menerapkan ilmunya. ${ }^{26}$ Keenam, pendidikan adalah keteladanan (uswah hasanah) dari seorang guru, karena apa yang dilakukan guru akan selalu menjadi acuan siswa untuk ditiru. ${ }^{27}$

\section{b. Pendidikan Integral}

K.H. Abdullah Syukri Zarkasyi mengembangkan konsep pendidikan integral yang dipengaruhi konsep integrasi ilmu dari K.H. Ahmad Dahlan. Konsep pendidikan integral yang dikembangkan oleh K.H. Abdullah Syukri Zarkayi tidak terbatas pada aspek

${ }^{23}$ Abdullah Syukri Zarkasyi, Bekal untuk pemimpin; Pengalaman Memimpin Gontor, op.cit.,hlm. 32.

${ }^{24}$ Ibid.,hlm. 35.

25Ibid., hlm.29.

${ }^{26}$ Ibid.,hlm. 37-38.

${ }^{27}$ Ibid.,hlm. 39. 
keilmuan saja, tetapi dengan menerapkan totalitas kehidupan. Totalitas berarti berpikir secara menyeluruh dengan bekerja keras dan dilakukan secara total. Pendidikan integral yang diterapkan di PMDG dilaksanakan dengan cara menyatukan jiwa, pikiran, cita-cita, idealisme, dan orientasi yang telah dirancang di PMDG. $^{28}$

Pendidikan integral mencakup juga ilmu-ilmu yang dipelajari. Ilmu agama dan ilmu sekuler harus dipelajari semuanya sebagai satu kesatuan. Pendidikan di PMDG tidak mengenal dikotomi antara ilmu agama dan ilmu sekuler, karena status ontologis ilmuilmu tersebut pada hakekatnya adalah sama. Sikap dikotomis dalam pendidikan hanya akan menjadikan proses pendidikan tidak berfungsi secara maksimal. ${ }^{29}$

\section{c. Berorientasi Pendidikan Lokal}

\section{(Pesantren)}

Pendidikan lokal yang dimaksud di sini adalah sistem pendidikan asrama model pesantren ${ }^{30}$ sistem asrama besarmanfaatnya dalam proses

${ }^{28}$ Abdullah Syukri Zarkasyi, "Integritas di Lingkungan Pesantren", Majalah Gontor, Edisi 08, Tahun XII, Safar-RabiulAwal 1436/Desember 2014, hlm. 30.

${ }^{29}$ H.M. Yunus Abu Bakar, (2007), "Konsep Pemikiran Pendidikan K.H. Imam Zarkasyi dan Implementasinya pada Pondok Pesantren Alumni", Disertasi, UIN SunanKalijaga, hlm. 8-9. ${ }^{30} \mathrm{Ki}$ Hadjar Dewantara menyebutnya sebagai pawiyatan. Ki Hadjar Dewantara, op.cit.,hlm. 41. pendidikan, karena sistem ini tidak sekedar memberikan pengajaran hidup secara pedagogik, tetapi juga memberikan pelajaran dari pedagogik yang hidup. ${ }^{31}$

Pendidikan model pesantren menyatukan tiga komponen pendidikan masyarakat Indonesia yang terdiri dari keluarga, sekolah, dan masyarakat. Ketiganya berada dalam satu lingkungan yang terpadu, sehingga lebih memungkinkan untuk menciptakan suasana yang kondusif bagi pencapaian tujuan pendidikan. ${ }^{32}$ Pendidikan model pesantren memiliki, setidaknya, delapan karakteristik. Pertama, adalah sistem pendidikan asrama yang betul-betul menerapkan tri pusat pendidikan secara terpadu. Kedua, memiliki konsep self governance dalam proses pendidikan yang berarti santri adalah subyek pendidikan.

Ketiga, pesantren adalah lembaga pendidikan yanng berasal dari, dikelola oleh, dan berkiprah untuk masyarakat. Keempat, berorientasi kemasyarakatan. Kelima, pengajaran (formal) dan pendidikan (informal) terintegrasi dalam satu kesatuan, Keenam, hubungan antara anggota masyarakat di pesantren berlangsung dalam suasana kekeluargaan, Ketujuh, memiliki prinsip

\footnotetext{
${ }^{31}$ Ki Hadjar Dewantara, ibid.

${ }^{32}$ Abdullah Syukri Zarkasyi, Manajemen Pesantren, op.cit.,hlm. 32.
} 
keikhlasan, perjuangan, pengorbanan, kesederhanaan, kemandirian, dan persaudaraan. Kedelapan, kyai atau pimpinan sekolah, selain sebagai tokoh sentral, juga berperan sebagai moral force bagi para santri dan seluruh penghuni pesantren.

Hal ini merupakan kondisi pokok dalam dunia pendidikan, tetapi jarang dijumpai dalam sistem pendidikan selain pesantren. ${ }^{33}$ Pengaruh dari Ki Hadjar Dewantara dalam mengembangkan kelokalan tampak dalam pemikiran K.H. Abdullah Syukri Zarkasyi ketika melaksanakan pendidikan di PMDG.

Perbedaan antara keduanya adalah, apabila Ki Hadjar Dewantara melaksanakan pendidikan dengan memberikan suasana nyaman di lembaga pendidikan tersebut dan melarang adanya paksaan dalam proses pendidikan, maka K.H. Abdullah Syukri Zarkasyi justru memandang bahwa pendidikan dilaksanakan dengan pemaksaan dan pemberian tekanantekanan untuk melatih siswa menyelesaikan persoalan kehidupan. Pemaksaan dan pemberian tekanan inilah yang melahirkan sebuah kebiasaan, dari kebiasaan itulah akanmelahirkan sebuah pola hidup. Konsepini merupakan aplikasi dari AlQuran surat Al-'Ankabut ayat 6:

${ }^{33}$ Ibid.,hlm. 32-33.

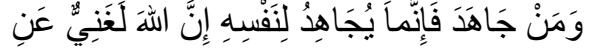<smiles>[AlH2]</smiles>

Artinya:"Dan Barang siapa yang berjihad (bersungguh-sungguh), maka sesungguhnya jihadnya itu adalah untuk dirinya sendiri. Sesungguhnya Allah benar-benar Maha Kaya (tidak memerlukan sesuatu) dari semesta alam. ${ }^{34}$

5. Pengaruh Pemikiran K.H. Abdullah Syukri Zarkasyi dalam Bidang Pendidikan

a. Pengaruh Internal

1) Berkembangnya PMDG Menjadi Sembilan Belas Cabang pada Masa Kepemimpinan K.H. Abdullah Syukri Zarkasyi.

Perkembangan PMDG menjadi sembilan belas cabang pada masa kepemimpinan K.H. Abdullah Syukri Zarkasyi adalah bukti bahwa sistem pendidikan di PMDG dapat diterima dan dianggap baik oleh masyarakat. Indikator dari baik buruknya suatu sistem pendidikan adalah:

a) Sistem pendidikan dapat diuji kelayakannya dengan cara dibandingkan dengan yang lain.

b) Sistem pendidikan harus mampu bertahan dan tidak mudah berubah.

c) Sistem pendidikan harus menghasilkan alumni yang mampu bersaing di masyarakat. ${ }^{35}$

\footnotetext{
${ }^{34}$ Ibid.,hlm. 61.

${ }^{35}$ Abdullah Syukri Zarkasyi, "Ketahanan Sistem Pendidikan”, Majalah Gontor, Edisi 09, Tahun XII,
} 
Sistem pendidikan model PMDG terbukti mampu bertahan dan terbebas dari berbagai macam kepentingan, terutama kepentingan politik. K.H. Abdullah Syukri Zarkasyi meneruskan dan mengembangkan sistem yang telah digagas oleh ayahnya, K.H. Imam Zarkasyi, sejak tahun $1926 .{ }^{36}$

2) Meningkatnya Jumlah Santri dan Tenaga Pengajar di PMDG

Meningkatnya kepercayaan masyarakat terhadap sistem pendidikan di PMDG yang dikembangkan oleh K.H. Abdullah Syukri Zarkasyi menyebabkan meningkatnya jumlah santri dan tenaga pengajar di PMDG. Data jumlah santri dan guru di PMDG selama tiga tahun terakhir adalah 21.255pada tahun 2014, 22.320 pada 2015, dan 23.506 pada 2016. Presentase kenaikan jumlah santri dan tenaga pengajar di PMDG selamatigatahun terakhir menunjukkan angka $5 \%$ per tahun. ${ }^{37}$

Januari 2015/RabiulAwal-RabiulAkhir $\quad$ 1432, hlm. 30 .

${ }^{36}$ K.H. Abdullah Syukri Zarkasyi memimpin PMDG pada dua masa, masa Orde Baru dan Reformasi. Sistem pendidikan di PMDG tidak terpengaruh sama sekali dengan perubahan tatanan sistem politik nasional, bahkan pada masa reformasi sistem di PMDG semakin diakui eksistensinya melalui Surat Keputusan Mendiknas No.105/0/2000 tentang persamaan status PMDG dengan Sekolah Menengah Umum (SMU).

${ }^{37}$ Warta Dunia Pondok Modern Darussalam Gontor, Vol. 67, 68, 69

\section{b. Pengaruh Eksternal}

1) Pengakuan terhadap Sistem

\section{Pendidikan PMDG}

Sistem pendidikan di PMDG yang semakin diterima oleh masyarakat dibuktikan dengan banyaknya didapat. Pertama adalah pengakuan dari pemerintah Republik Indonesia disamakan dengan Madrasah Tsanawiyah dan Aliyah Negeri pada tahun 1998 melalui Surat Keputusan Binbaga Islam No. E.IV/PP.03.2/ KEP/64/98. Selanjutnya Kementerian Pendidikan Nasional juga mengakui sistem pendidikan di PMDG dan menyamakannya dengan Sekolah Menengah Umum (SMU) melalui Surat Keputusan Mendiknas No.105/0/2000.

Kedua, adalah penghargaan dari Presiden Mesir, Housni Mubarok tahun 2006 di Madinah Nasr City. K.H. Abdullah Syukri mendapatkan Bintang Kehormatan Ilmu dan Seni (Wisam Jumhuriyyah Misr al'Arabiyah 'AlaDarajah Al-Ula Li Al-Ulum wa Al-Funun). Penghargaan ini diberikan karena kontribusinya dalam pengembangan agama Islam, berdasarkan perkembangan dari PMDG yang dipimpinnya.

Ketiga, adalah Pengakuan dari Dunia Internasional tentang sistem perguruan tinggi milik PMDG. Pengakuan dari dunia internasional ini berdasarkan ditunjuknya ISID, perguruan tinggi 
PMDG, sebagai tuan rumah Konferensi Internasional Liga Universitas Islam pada tahun 2007. Konferensi ini dihadiri oleh seratus tujuh rektor perguruan tinggi Islam dari berbagai negara. ${ }^{38}$

2) Gagasan Tokoh Masyarakat yang dipengaruhi oleh Sistem Pendidikan di PMDG

\section{a) Sutrisno Bachir}

Sutrisno mengaku jika PMDG memberikannya inspirasi terutama tentang model pendidikan yang diterapkan di sana. Menurutnya, pendidikan di PMDG merupakan model ideal untuk diterapkan di tingkat nasional.

Jiwa wirausaha yang dilaksanakan di PMDG merupakan suatu hal yang harus dicontoh untuk mendidik siswa tentang kemandirian. Jiwa wirausaha dan kemandirian inilah yang harus dimiliki oleh segenap masyarakat untuk membantu Indonesia keluar dari krisis yang terus melanda. ${ }^{39}$

\section{b) K.H. Yusuf Mansur}

Yusuf Mansur banyak mendapatkan inspirasi dari PMDG ketika dia mendirikan pondok Darul Quran. Banyak ajaran-ajaran dan filsafat hidup di PMDG yang diaplikasikan di pondok yang dia pimpin saat ini. Yusuf Mansur merasa

\footnotetext{
${ }^{38}$ Warta Dunia Pondok Modern Darussalam Gontor, Vol. 60, op.cit.,hlm. 40.

${ }^{39}$ Warta Dunia Pondok Modern Darussalam Gontor, Vol. 62, op.cit.,hlm. 100.
}

menjadi bagian dari PMDG meskipun dia bukan alumni dari pondok ini.

Hal ini dibuktikan dengan fasilitas yang dia berikan ketika acara Forum Pesantren Alumni Gontor (FPAG) yang dilaksanakan di Banten pada 22 Januari 2016.40 Yusuf Mansur juga meminta alumni-alumni PMDG mengajar di Pondok Darul Quran, untuk mentransformasikan nilai-nilai yang ada di PMDG ke pondok tersebut.

\section{c) Pondok Pesantren Al-Muttaqin}

Pondok Pesantren Al-Muttaqin didirikan oleh K.H. Yatiman di Desa Buper Waena, Kecamatan Heram, Kabupaten Jayapura pada tahun 2007. Pondok ini merupakan salah satu pelopor pondok pesantren yang di dirikan di Papua sebagai syiar Islam di sana.

Pendirian Pondok Pesantren AlMuttaqin sendiri terinspirasi dari kesuksesan PMDG dalam membangun jaringan pondok pesantren di Indonesia.Hal ini terlihat dari sistem pendidikannya yang hampir semuanya mengadopsi dari sistem yang ada di PMDG. Alumni PMDG juga dikirimkan ke Pondok Al-Muttaqin, atas permintaan K.H. Yatiman, setiap tahun guna

${ }^{40}$ Warta Dunia Pondok Modern Darussalam Gontor, Vol. 69, op.cit.,hlm. 61. 
memenuhi kebutuhan dewan guru yang ada di sana. ${ }^{41}$

\section{Penutup}

Berdasarkan hasil penulisan pada bab-bab sebelumnya, maka diperoleh kesimpulan, sebagai berikut:

1. Pendidikan harus dibangun dengan landasan ajaran-ajaran agama, nilai kemanusiaan, dan berwawasan kebangsaan. K.H. Abdullah Syukri Zarkasyi memiliki pandangan tersendiri tentang definisi pendidikan. Baginya pendidikan adalah segala sesuatu yang kita lihat, kita dengar, dan kita rasakan. Pendidikan yang baik adalah pendidikan yang mengajarkan totalitas kehidupan yang dilaksanakan dengan mengendalian peserta didik dengan total melalui kegiatan ekstrakulikuler, intrakulikuler, dan kokulikuler dalam rangka mendidik pola kecerdasan peserta didik, baik secara intelektual-emosional, sosial, maupun spiritual.Gagasan K.H. Abdullah Syukri Zarkasyi tentang pendidikan mengerucut kepada satu tema, yaitu lembaga pendidikan dengan sistem asrama yang tidak sekedar memberikan pengajaran hidup secara pedagogik, tetapi juga memberikan pelajaran dari pedagogik yang hidup.

2. Pengaruh internal dari pemikiran Kyai Syukri adalah, pada masa kepemimpinannya PMDG berkembang

${ }^{41}$ Wawancara dengan Faqihuddin, putra K.H. Yatiman, pada Minggu, 12 Juni 2016. menjadi 18 cabang yang tersebar di seluruh Indonesia. Hal ini disertai dengan meningkatnya jumlah santri dan guru yang ada di PMDG. Presentase kenaikan jumlah santri dan guru di PMDG selama tiga tahun terakhir mencapai angka 5\% per tahun.Pengaruh eksternal dari pemikiran K.H. Abdullah Syukri Zarkasyi adalah pengakuan dari berbagai pihak tentang sistem pendidikan di PMDG.

Pengakuan tersebut antara lain berasal dari pemerintah Republik Indonesia dengan menyamakan status PMDG dengan SMU pada tahun 2000, penghargaan dari Presiden Mesir pada tahun 2006, pengakuan dari Dunia Internasional tentang sistem perguruan tinggi milik PMDG dengan mengadakan Konferensi Internasional Liga Universitas Islam pada tahun 2007, dan pengakuan dari Kementerian Pendidikan dan Pengajaran Mesir dengan memberikan lima puluh beasiswa setiap tahun kepada alumni PMDG untuk melanjutkan pendidikan tinggi di Universitas AlAzhar.Pengaruh eksternal selanjutnya adalah banyaknya tokoh masyarakat yang terinspirasi perkembangan PMDG selama kepemimpinan K.H. Abdullah Syukri.

Penulis memberikan tiga contoh tokoh masyarakat yang terinspirasi dari PMDG. Pertama, adalah Sutrisno Bachir yang terinspirasi akan jiwa wirausaha 
yang dilaksanakan di PMDG, sehingga PMDG menjadi lembaga pendidikan yang mandiri. Kedua, adalah K.H. Yusuf Mansur yang terkesan dengan nilai-nilai dan filsafat hidup di PMDG, sehingga dia meminta alumni-alumni PMDG untuk mengajar di pondok Darul Quran yang dia pimpin saat ini.

Ketiga, adalah K.H. Yatiman yang terinspirasi kesuksesan K.H. Abdullah Syukri dalam membangun jaringan pesantren di seluruh Indonesia. K.H. Yatiman kemudian mendirikan pesantren Al-Muttaqin sebagai media dakwah di Jayapura, dengan mengadopsi sistem yang ada di PMDG.

\section{DaftarPustaka}

\section{Buku}

Abdullah Syukri Zarkasyi. 2011. Bekal untuk Pemimpin; Pengalaman Memimpin Gontor. Ponorogo: Trimurti Press.

Abdullah Syukri Zarkasyi. 2005. Manajemen Pesantren. Ponorogo: Trimurti Press.

Anonim. 2009. Konstitusi UUD 1945 dan Amandemen I,II, III \& IV. Yogyakarta: Pustaka Timur.

As'aril Muhajir. 2011. Ilmu Pendidikan Persperktif Kontekstual. Yogyakarta: ArRuzz Media.

Creswell, John W. "Research Design: Qualitative, Quantitative, and Mixed Approaches". Alih Bahasa. Ahmad Fawaid. 2010. Research Design: Pendekatan Kualitatif, Kuantitatif, dan Mixed. Yogyakarta: Pustaka Pelajar.

H.A.R Tilaar. 2009. Membenahi Pendidikan Nasional. Jakarta: Rineka Cipta.

H.A.R. Tilaar. 2010. Paradigma Baru Pendidikan Nasional. Jakarta: Rineka Cipta.
H.E. Mulyasa. 2015. Revolusi Mental dalam Pendidikan. Bandung: Rosda.

Helius Sjamsuddin. 2007. Metodologi Sejarah. Yogyakarta: Ombak.

Ki Hadjar Dewantara. 2009. Menuju Manusia Merdeka. Yogyakarta: Leutika.

Kuntowijoyo. 1995. Pengantar Ilmu Sejarah. Yogyakarta: Bentang Pustaka.

Muhammad Rifa'i. 2010. Sejarah Pendidikan Nasional. Yogyakarta: Ar-Ruzz Media.

Suyanto, "Tantangan Global Pendidikan Nasional, Pendidikan untuk Indonesia Baru", Dalam A. Suhaenah Suparno dan H.A.R. Tilaar (Kon). 2002.70 Tahun Prof. Dr. H.A.R. Tilaar. Jakarta: Grasindo.

Suyanto. 2006. Dinamika Pendidikan Nasional dalam Percaturan Dunia Global. Jakarta: PSAP.

Winarno Surakhmad. 2009. Pendidikan Nasional, Strategi dan Tragedi. Jakarta: Kompas.

\section{Majalah}

Abdullah Syukri Zarkasyi, "Ikhlas", Majalah Gontor, Edisi 07, Tahun XII, November 2014/Muharram-Safar 1436, hlm. 30.

Abdullah Syukri Zarkasyi, "Integritas di Lingkungan Pesantren”, Majalah Gontor, Edisi 08, Tahun XII, Safar-Rabiul Awal 1436/Desember 2014, hlm. 30.

Abdullah Syukri Zarkasyi, "Ketahanan Sistem Pendidikan", Majalah Gontor, Edisi 09, Tahun XII, Januari 2015/Rabiul Awal-Rabiul Akhir 1432, hlm. 30 .

Imam Zarkasyi, "Panca Jiwa Pondok Pesantren”, Majalah Gontor, Edisi 06, Tahun XII, Oktober 2014/DzulhijjahMuharram 1435, hlm. 96.

\section{Disertasi}

H.M. Yunus Abu Bakar. 2007. “Konsep Pemikiran Pendidikan K.H. Imam Zarkasyi dan Implementasinya pada Pondok Pesantren Alumni”. Disertasi. UIN Sunan Kalijaga. 
48 IJURNAL AGASTYA VOL 08 NO 01 JANUARI 2018

\section{Buletin}

Warta DuniaPondok Modern Darussalam Gontor, Vol. 58, Sya'ban 1426/2005.

Warta DuniaPondok Modern Darussalam Gontor, Vol. 59, Sya'ban 1427/2006.

Warta DuniaPondok Modern Darussalam Gontor, Vol. 60, Sya'ban 1428/2008.

Warta DuniaPondok Modern Darussalam Gontor, Vol. 61, Sya'ban 1429/2006.

Warta DuniaPondok Modern Darussalam Gontor, Vol. 62, Sya'ban 1430/2009. 